\title{
Experimental models for the autoimmune and inflammatory blistering disease, Bullous pemphigoid
}

\author{
Lisa Leighty $\cdot$ Ning Li $\cdot$ Luis A. Diaz $\cdot$ Zhi Liu
}

Received: 30 April 2007 / Revised: 15 August 2007 / Accepted: 29 August 2007 / Published online: 19 September 2007

(C) Springer-Verlag 2007

\begin{abstract}
Bullous pemphigoid (BP) is a subepidermal skin blistering disease characterized immunohistologically by dermal-epidermal junction (DEJ) separation, an inflammatory cell infiltrate in the upper dermis, and autoantibodies targeted toward the hemidesmosomal proteins BP230 and BP180. Development of an IgG passive transfer mouse model of BP that reproduces these key features of human $\mathrm{BP}$ has demonstrated that subepidermal blistering is initiated by anti-BP180 antibodies and mediated by complement activation, mast cell degranulation, neutrophil infiltration, and proteinase secretion. This model is not compatible with study of human pathogenic antibodies, as the human and murine antigenic epitopes are not cross-reactive. The development of two novel humanized mouse models for the first time has enabled study of disease mechanisms caused by BP autoantibodies, and presents an ideal in vivo system to test novel therapeutic strategies for disease management.
\end{abstract}

Keywords Autoimmune disease - Basement membrane . Hemidesmosome · Humanized animal model .

Inflammation

\section{Etiology of bullous pemphigoid}

In 1953, Lever [28] described bullous pemphigoid (BP) as a subepidermal blistering disorder primarily seen in the elderly. Lesional/perilesional skin of BP patients exhibits detachment of the basal keratinocytes of the epidermis from

L. Leighty $\cdot$ N. Li $\cdot$ L. A. Diaz $\cdot$ Z. Liu $(\bowtie)$

Departments of Dermatology, Microbiology and Immunology,

University of North Carolina School of Medicine,

3100 Thurston Bowles, Chapel Hill, NC 27599, USA

e-mail: zhiliu@med.unc.edu the dermis at the level of the lamina lucida [55], resulting in tense, fluid-filled vesicles. BP is both an inflammatory disease and an autoimmune disease, characterized by an inflammatory infiltrate at the site of the dermal-epidermal junction separation and by the deposition of autoantibodies and complement components along the basement membrane zone (BMZ).

A number of inflammatory cells are present in the upper dermis and bullous cavity, including eosinophils (the predominant cell type), neutrophils, lymphocytes, and monocytes/macrophages. Both intact and degranulating eosinophils, neutrophils, and mast cells (MC) are found in the dermis. Local activation of these cells may occur via the multiple inflammatory mediators present in the lesional skin and/or blister fluids, including (a) granular proteins derived from degranulated leukocytes, such as eosinophil cationic protein (ECP), eosinophil major basic protein (MBP), and neutrophil-derived myeloperoxidase (MPO) [1, $4,8]$ and (b) chemoattractants and cytokines, such as C5a fragments, histamine, leukotriene B4, interleukin-1, -2, -4, $5,-6,-8,-15$, TNF- $\alpha$, IFN- $\gamma$, RANTES, and eotaxin $[9,10$, $21,22,46,47,48,58,62]$. Additionally, several proteinases are found in BP blister fluid, including plasmin, collagenase, elastase, and 92-kDa gelatinase [2, 14, 24, 27, 44, 45, $52,57]$. These proteolytic enzymes may play a crucial role subepidermal blister formation in BP via their ability to degrade extracellular matrix proteins.

BP patients generate a polyclonal repertoire of autoantibodies that bind to the BMZ and activate complement, as well as circulating autoantibodies [20]. These autoantibodies target two major hemidesmosomal antigens of $230 \mathrm{kD}$ (BP230 or BPAG1) and $180 \mathrm{kD}$ (BP180, BPAG2, or type XVII collagen) $[25,40,56,57]$. BP230, a component of the hemidesmosomal plaque, is an intracellular protein, while BP180 is a type II transmembrane protein [19, 23, 56]. Like BP230, 
BP180's amino-terminal portion localizes to the intracellular hemidesmosomal plaque [15, 18, 19]. Its carboxyl-terminal region extends into the extracellular milieu of the BMZ, making it the preferred target for pathogenic BP autoantibodies. This antigenic extracellular region consists of 15 collagen domains separated from one another by non-collagen sequences. The largest of these non-collagen domains is referred to as NC16A. Epitope mapping studies indicate that BP autoantibodies of IgE and IgG isotypes and IgG1 and IgG4 subclasses recognize multiple epitopes that cluster within BP180 NC16A [3, 11, 16, 26, 63]. Serum levels of these autoantibodies are correlated with disease severity [11, 17, 49].

Most BP patients elicit a cell mediated autoimmune response in addition to the humoral response described. Autoreactive CD4+ $\mathrm{T}$ lymphocytes recognize epitopes within the extracellular region of BP180, primarily in the NC16A domain $[5,29]$. These $\mathrm{T}$ cells express memory cell surface markers and exhibit a Th1/Th2 mixed cytokine profile. These studies suggest that BP is a T and B cell-dependent and antibody-mediated skin autoimmune disease.

\section{Development of murine IgG passive transfer model of BP}

The strong correlation between BP disease severity and serum BP180-specific autoantibody levels suggests that BP blister formation is mediated by autoantibodies. Early attempts to demonstrate the pathogenicity of patient autoantibodies via a passive transfer mouse model were unsuccessful because BP autoantibodies that react with an immunodominant and potentially pathogenic epitope in BP180-NC16A fail to cross-react with the murine form of this autoantigen (mBP180 NC14A) [30]. In 1993, Liu et al. [30] devised a strategy to overcome this difficulty and generated rabbit polyclonal antibodies raised against a cloned segment of mBP180 NC14A and passively transferred the purified rabbit anti-mBP180 IgG into neonatal BALB/c mice. The injected animals developed a disease that exhibited the following hallmarks of human BP: (a) clinical skin lesions; (b) in vivo deposition of rabbit $\operatorname{IgG}$ and mouse C3 at the basement membrane by direct IF; (c) dermal-epidermal separation and an extensive inflammatory cell infiltration by H\&E staining [30]. This infiltrate includes neutrophils, lymphocytes, and monocytes/macrophages, with neutrophils being the predominant cells [7, 30].

\section{Immunopathogenesis of experimental BP in the murine model}

Development of an in vivo system to study an experimental BP model has allowed for great progress in defining the etiopathogenesis of disease. Specifically, the roles of pathogenic antibodies, the complement system, inflammatory cells, and proteolytic enzymes have all been elucidated in the context of the murine IgG passive transfer model.

Injection of anti-mBP180 IgG initiated subepidermal blister formation, and the levels of circulating anti-mBP180 antibodies completely determine disease onset and severity [30, 34]. Epitope mapping studies demonstrated that pathogenic anti-BP180 antibodies recognize a 9-12 amino acid stretch within the murine BP180 NC14A region of the antigen [31]. This epitope overlaps the region of the human BP180 NC16A that contains the immunodominant epitopes recognized by human BP autoantibodies, supporting the relevance of this murine system as a model for human disease.

Using mice deficient in different inflammatory cell types, it has been demonstrated that mast cells, macrophages, and neutrophils, but not $\mathrm{T}$ and $\mathrm{B}$ lymphocytes, play a direct role in subepidermal blistering in experimental BP [7]. AntimBP180 autoantibodies trigger skin blistering in wild-type mice and mice deficient in $\mathrm{T}, \mathrm{B}$, or both $\mathrm{T}$ and $\mathrm{B}$ cells, but fail to induce lesions in mice deficient in mast cells, macrophages, or neutrophils. Quantification of disease severity in these mice demonstrated that mast cells and neutrophils play a key role in experimental BP.

Autoantibodies bind to basement membrane antigens and activate complement in human BP. In the rabbit antimBP180 IgG-induced BP, complement activation is absolutely required. Both $\mathrm{BALB} / \mathrm{c}$ mice depleted of complement (by pretreatment with cobra venom) and C5-deficient mice are resistant to experimental $\mathrm{BP}$, and reconstitution of the C5-deficient mice with C5a restores susceptibility [32]. $\mathrm{F}(\mathrm{ab})_{2}$ fragments generated from the pathogenic antimBP180 IgG cannot induce subepidermal blisters in C5sufficient mice [32]. Mice deficient in complement component C4 (specific for the classical and lectin pathways), but not in factor B (specific for the alternative pathway), are resistant to BP [41]. Wild-type mice depleted of complement component C1q (specific for the classical pathway) fail to develop BP skin lesions when injected with pathogenic IgG [41]. These data suggest that the classical pathway of the complement activation plays a major role in development of disease, namely through the generation of C5a that in turn activates MCs [6].

Mice injected with pathogenic anti-mBP180 antibodies exhibit extensive MC degranulation in the lesional skin, similar to that observed in human BP $[6,59]$. MC-deficient mice are resistant to experimental $\mathrm{BP}$, but reconstitution of these mice with MCs restores their susceptibility to disease. MC activation precedes neutrophil infiltration, and either the absence of MCs or the inhibition of MC degranulation prevents neutrophil infiltration and blister formation. However, MC-deficient mice reconstituted locally with neutrophils, 
or injected locally with neutrophil chemoattractants IL-8 or TNF- $\alpha$ form blisters in response to anti-mBP180 IgG. These results suggest that mast cells release proinflammatory cytokines critical for neutrophil recruitment [6].

Experimental BP requires neutrophil infiltration, and there is a direct correlation between disease severity and number of infiltrating neutrophils [33]. Depletion of neutrophils, or disruption of the events upstream of neutrophil infiltration (complement activation and MC degranulation), renders mice resistant to $\mathrm{BP}$ blister formation. However, complement system and MC deficiencies only confer protection from the pathogenic effects of BP180 autoantibodies if neutrophil infiltration is blocked as a consequence; that is, complement activation and MC degranulation are only critical to disease progression in their roles of neutrophil recruitment. This suggests that infiltrating neutrophils are the cells that directly cause tissue injury in the dermal-epidermal junction, leading to BP skin blisters.

Upon activation through molecular interactions between the Fc $\gamma$ IIIR on the neutrophil cell surface and the Fc portion of pathogenic anti-mBP180 IgG [61], infiltrating neutrophils secrete proteolytic enzymes known to degrade the extracellular matrix, including neutrophil elastase (NE) and gelatinase B (GB). A deficit of either of these two enzymes blocks blister formation in mice $[35,36]$. In vitro, although both GB and NE are capable of degrading the recombinant BP180 protein, only NE produces DEJ separation when incubated with skin sections $[36,52]$. In vivo, the degradation of BP180 depends on NE activity. Taken together, these findings suggest that GB acts upstream of NE. Specifically, GB proteolytically inactivates the physiological inhibitor of NE ( $\alpha 1$-proteinase inhibitor), which allows for unmitigated NE cleavage of extracellular matrix proteins (including BP180), resulting in DEJ separation [37].

\section{Development of the humanized murine passive transfer model}

While the rabbit anti-mBP180 IgG passive transfer model has provided invaluable insight to the key steps in BP disease development, it does not allow for experimentation with BP autoantibodies isolated from human clinical samples. A second animal model, in which rabbit antibodies directed against the extracellular domain of hamster BP180 (NC16A region) are transferred into neonatal hamsters, also lacks cross-reactivity with antibodies directed against human BP180 [59]. To assess the pathogenicity of human anti-BP180 autoantibodies, we generated a novel mouse strain in which the murine BP180NC14A was replaced with the homologous human BP180NC16A epitope cluster region [38]. The humanized $\mathrm{NC16A}(\mathrm{NC16+/+)}$ mice injected with anti-BP180NC16A autoantibodies develop $\mathrm{BP}$, and the disease development depends on complement, mast cells and neutrophils (Fig. 1).

Using the $\mathrm{NC} 16 \mathrm{~A}+/+$ mice and BP patients' sera, we mapped the pathogenic epitope of BP180 in vivo [39]. IgG passive transfer experiments identified one pathogenic epitope (referred to as BP180NC16A2.5). BP180NC16A2.5specific autoantibodies induced subepidermal blisters in the $\mathrm{NC} 16 \mathrm{~A}+/+$ mice, and these blisters were blocked by pretreatment with recombinant BP180NC16A2.5. We also found that the NC16A2.5 pretreated mice had significantly reduced levels of $\mathrm{BMZ}$-bound and circulating pathogenic
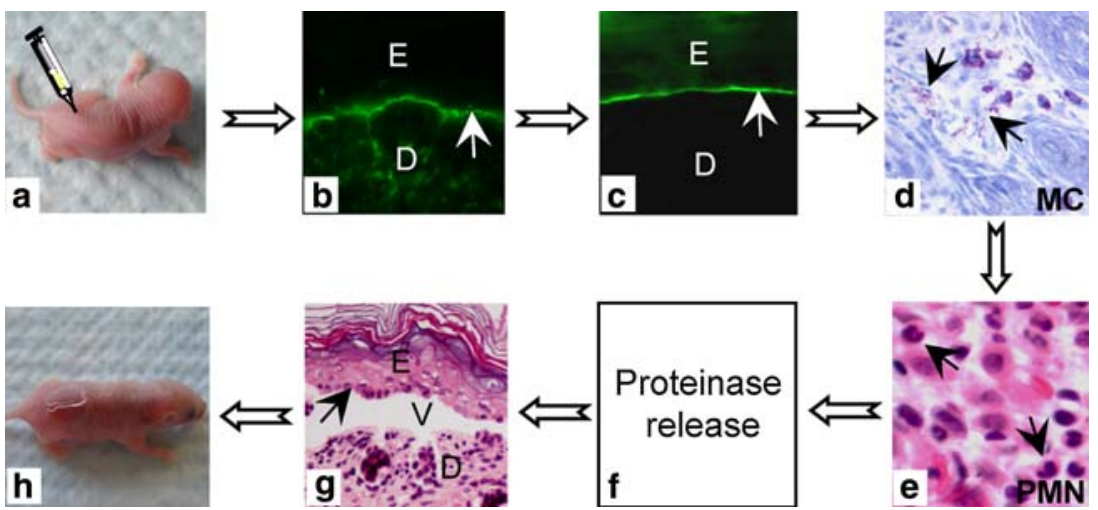

Fig. 1 Proposed mechanism of subepidermal blister formation in humanized NC16A mouse model of BP. Subepidermal blistering is an inflammatory process involved in following steps: a anti-BP180 autoantibodies are injected into $\mathrm{NC16}$ A mice; $\mathbf{b}$ pathogenic antibodies bind to the pathogenic epitope of BP180 antigen in basal keratinocytes (BK); c the molecular interaction between BP180 antigen and antiBP180 IgG activates the complement system $\left(\mathrm{C}^{\prime}\right)$ as evidenced by $\mathrm{BMZ}$ deposition of mouse $\mathrm{C} 3 ; \mathbf{d} \mathrm{C}^{\prime}$ activation products $\mathrm{C} 3 \mathrm{a}$ and $\mathrm{C} 5 \mathrm{a}$

cause mast cells $(M C)$ to degranulate; e $M C$ activation leads to neutrophil $(P M N)$ recruitment; f infiltrating $P M N s$ bind to the BP180-antiBP180 immune complex via the molecular interaction between $\mathrm{Fc} \gamma$ receptors on neutrophils and the Fc domain of anti-BP180 IgG. Activated $P M N s$ release proteolytic enzymes; g proteolytic enzymes degrade BP180 and other extracellular matrix proteins, leading to dermal-epidermal junction separation; $\mathbf{h}$ pathogenic antibody-injected mice develop clinical blisters 
antibodies and showed reduced complement activation, mast cell degranulation and neutrophil infiltration. These results suggest that targeting the pathogenic epitope specifically could be a new therapeutic strategy to treat BP.

A second humanized animal model has been developed by Nishie et al. [42, 43] that replaces the mouse BP180 (COL17) with the human analogue. Upon injection of human anti-BP180 autoantibodies, these mice reproduce the DEJ separation at the lamina lucida, the deposition of human IgG along the DEJ, and an inflammatory cell infiltrate consisting of neutrophils and eosinophils seen in human disease. The pathogenic effects of the autoantibody injection are ablated by pretreatment with a 77-amino acid peptide fragment of COL17 NC16A, referred to as R1. These studies further support the therapeutic potential of employing decoy peptides to block the pathogenic epitope.

\section{Relevance of murine and humanized passive transfer models to human BP}

Both in vitro and in vivo data demonstrate that BP180 is the target for pathogenic autoantibodies in BP (Table 1). While clinical human BP and experimental murine and humanized murine BP closely mimic each other at the clinical, histological, and immunological levels, the IgG passive transfer models do not reflect the large number of eosinophils typically found in the inflammatory infiltrate of human BP lesional skin. Some patients do exhibit neutrophil-rich pemphigoid, indicating that the neutrophil-mediated blistering observed in these mouse models may be one of several disease mechanisms that contribute to the formation and persistence of subepidermal blisters. The presence of a neutrophil-rich inflammatory infiltrate in the two humanized mouse models, as well as in the aforementioned hamster model, lend credence to a neutrophil-mediated disease mechanism. Furthermore, findings that in vitro DEJ separation induced by human BP autoantibodies specific for BP180NC16A depends on neutrophils [51] and neutrophilderived elastase and gelatinase B [50], and that BP180 degradation by human BP blister fluid depends on neutrophil elastase activity [57] support this theory. Taken together, these findings strongly suggest that like the $\operatorname{IgG}$ passive transfer model of BP, neutrophils may be responsible for subepidermal blister formation in human BP, at least in those patients who show neutrophil infiltration in their lesional/perilesional skin. The humanized mouse models do not yet offer insight to an eosinophil-mediated mechanism of disease progression, leaving the role of these inflammatory cells, if there is any, yet to be discovered. It is possible that these established mouse models, without additional experimental manipulations, may not be able to fully duplicate human BP pathology related to eosinophil infiltration;
Table 1 In vitro and in vivo evidence of pathogenicity of anti-BP180 antibodies

\begin{tabular}{|c|c|c|}
\hline System & Antibodies used & Reference \\
\hline \multicolumn{3}{|l|}{ In vitro } \\
\hline \multirow[t]{3}{*}{ Human skin section } & BP sera & [13] \\
\hline & $\begin{array}{l}\text { Anti-BP180NC16A } \\
\text { autoantibodies }\end{array}$ & {$[51]$} \\
\hline & Rabbit anti-BP180NC16A IgG & \\
\hline \multicolumn{3}{|l|}{ In vivo } \\
\hline Wild-type mice & Rabbit anti-murine BP180 IgG & {$[30]$} \\
\hline Hamster & Rabbit anti-hamster BP180 IgG & {$[60]$} \\
\hline $\begin{array}{l}\text { Humanized BP180 } \\
\text { mice }\end{array}$ & $\begin{array}{l}\text { Anti-BP180NC16A } \\
\text { autoantibodies }\end{array}$ & {$[38,39]$} \\
\hline $\begin{array}{l}\text { Humanized NC16A } \\
\text { mice }\end{array}$ & $\begin{array}{l}\text { Anti-BP180NC16A } \\
\text { autoantibodies }\end{array}$ & {$[42,43]$} \\
\hline
\end{tabular}

therefore, they may not be appropriate to study the role of eosinophils in BP.

Zone et al. [64] reported that IgE hybridoma to LABD97 antigen, a component of the shed ectodomain of BP180, when injected subcutaneously in SCID mice with engrafted human skin, induced eosinophil infiltration and histological blisters in engrafted human skin. Fairley et al. [12] also reported that total IgE isolated from BP sera, when injected into human skin grafted onto athymic nude mice, triggered a dermal infiltrate composed of neutrophils, eosinophils, and histological separation of the epidermis from the dermis. These findings implicate eosinophils in BP; however, a direct link between eosinophil recruitment and blistering in these human skin graft models needs to be established.

\section{Conclusions}

The murine $\operatorname{IgG}$ passive transfer model of BP developed by Liu et al. [30] has provided an invaluable tool for the dissection of the mechanism of disease progression. The development of humanized murine models of BP now provides unprecedented insight to the pathogenic role of the autoantibodies that mediate disease. Initial observations with these humanized models indicate that humanized mouse BP exhibits phenotypic and immunological similarities with murine and human BP. Additionally, these humanized models enabled the first identification of pathogenic epitopes in human disease. Blocking of the pathogenic epitope with decoy peptides, if they do not enhance the autoimmune responses, presents a novel clinical therapeutic strategy that may be very effective in abolishing the pathogenic effects of disease.

Acknowledgments This work was supported in part by U.S. Public Health Service NIH grants AI40768 and AI61430 (Z. L.), AR052109 
and AR053313 (N.L.), AR32599 and AR32081 (L.A. D.). L.L. is a recipient of a NIH Training grant (T32 AR07369).

\section{References}

1. Baba T, Sonozaki H, Seki K, Uchiyama M, Ikesawa Y, Torisu M (1976) An eosinophil chemotactic factor present in blister fluids of bullous pemphigoid patients. J Immunol 116:112-116

2. Baird J, Lazarus GS, Belin D, Vassalli JD, Busso N, Gubler P, Jensen PJ (1990) mRNA for tissue-type plasminogen activator is present in lesional epidermis from patients with psoriasis, pemphigus, or bullous pemphigoid, but is not detected in normal epidermis. $\mathbf{J}$ Invest Dermatol 95:548-552

3. Bernard P, Aucouturier P, Denis F, Bonnetblanc JM (1990) Immunoblot analysis of IgG subclasses of circulating antibodies in bullous pemphigoid. Clin Immunol Immunopathol 54:484-494

4. Borrego L, Maynard B, Peterson EA, George T, Iglesias L, Peters MS, Newman W, Gleich GJ, Leiferman KM (1996) Deposition of eosinophil granule proteins precedes blister formation in bullous pemphigoid. Comparison with neutrophil and mast cell granule proteins. Am J Pathol 148:897-909

5. Budinger L, Borradori L, Yee C, Eming R, Ferencik R, GrosseWilde H, Merk HF, Yancey KB, Hertl M (1998) Identification and characterization of autoreactive CD4+ T cell responses to bullous pemphigoid antigen 2 in patients and healthy controls. J Clin Invest 102:2082-2089

6. Chen R, Ning G, Zhao ML, Fleming MG, Diaz LA, Werb Z, Liu Z (2001) Mast cells play a key role in neutrophil recruitment in experimental bullous pemphigoid. J Clin Invest 108:1151-1158

7. Chen R, Fairley JA, Zhao M, Giudice GJ, Zillikens D, Diaz LA, Liu Z (2002) Macrophages, but not T and B lymphocytes are critical for subepidermal blister formation in experimental bullous pemphigoid: macrophage-mediated neutrophil infiltration depends on mast cell activation. J Immunol 169:3987-3992

8. Czech W, Schaller J, Schopf E, Kapp A (1993) Granulocyte activation in bullous diseases: release of granular proteins in bullous pemphigoid and pemphigus vulgaris. J Am Acad Dermatol 29:210-215

9. D'Auria L, Cordiali Fei P, Ameglio F (1999) Cytokines and bullous pemphigoid. Eur Cytokine Net 10:123-134

10. Diaz-Perez JL, Jordon RE (1976) The complement system in bullous pemphigoid. IV. Chemotactic activity in blister fluid. Clin Immunol Immunopathol 5:360-370

11. Dopp R, Schmidt E, Chimanovitch I, Leverkus M, Brocker EB, Zillikens D (2000) IgG4 and IgE are the major immunoglobulins targeting the NC16A domain of BP180 in bullous pemphigoid: serum levels of these immunoglobulins reflect disease activity. J Am Acad Dermatol 42:577-583

12. Fairley JA, Burnett CT, Fu CL, Larson DL, Fleming MG, Giudice GJ (2007) A pathogenic role for IgE in autoimmunity: bullous pempigoid IgE reproduces the early phase of lesion development in human skin grafted to nu/nu mice. J Invest Dermatol. doi: 10.1038/sj.jid.5700958

13. Gammon WR, Merritt CC, Lewis DM, Sams WM Jr, Carlo JR, Wheeler CE Jr (1982) An in vitro model of immune complex-mediated basement membrane zone separation caused by pemphigoid antibodies, leukocytes, and complement. J Invest Dermatol 78:285-290

14. Gissler HM, Simon MM, Kramer MD (1992) Enhanced association of plasminogen/plasmin with lesional epidermis of bullous pemphigoid. Br J Dermatol 127:272-277

15. Giudice GJ, Emery DJ, Diaz LA (1992) Cloning and primary structural analysis of the bullous pemphigoid autoantigen, BP-180. J Invest Dermatol 99:243-250
16. Giudice GJ, Emery DJ, Zelickson BD, Anhalt GJ, Liu Z, Diaz LA (1993) Bullous pemphigoid and herpes gestationis autoantibodies recognize a common non-collagenous site on the BP180 ectodomain. J Immunol 151:5742-5750

17. Haase C, Budinger L, Borradori L, Yee C, Merk HF, Yancey K, Hertl M (1998) Detection of IgG autoantibodies in the sera of patients with bullous and gestational pemphigoid: ELISA studies utilizing a baculovirus-encoded form of bullous pemphigoid antigen 2. J Invest Dermatol 110:282-286

18. Hopkinson SB, Riddelle KS, Jones JCR (1992) Cytoplasmic domain of the $180-\mathrm{kD}$ bullous pemphigoid antigen, a hemidesmosomal component: molecular and cell biologic characterization. J Invest Dermatol 99:264-270

19. Ishiko A, Shimizu H, Kikuchi A, Ebihara T, Hashimoto T, Nishikawa $\mathrm{T}$ (1993) Human autoantibodies against the $230-\mathrm{kD}$ bullous pemphigoid antigen (BPAG1) bind only to the intracellular domain of the hemidesmosome, whereas those against the $180-\mathrm{kD}$ bullous pemphigoid antigen (BPAG2) bind along the plasma membrane of the hemidesmosome in normal human and swine skin. J Clin Invest 91:1608-1615

20. Jordon RE, Beutner EH, Witebsky E, Blumental G, Hale WC, Lever WF (1967) Basement zone antibodies in bullous pemphigoid. JAMA 200:751-758

21. Katayama I, Doi T, Nishioka K (1984) High histamine level in the blister fluid of bullous pemphigoid. Arch Dermatol Res 276:126-127

22. Kawana S, Ueno A, Nishiyama S (1990) Increased levels of Immunorective leukotriene B4 in blister fluids of bullous pemphigoid patients and effects of a selective 5-lipoxygenase inhibitor on experimental skin lesions. Acta Derm Venereol 70:281-285

23. Klatte DH, Kurpakus MA, Grelling KA, Jones JCR (1989) Immunochemical characterization of three components of the hemidesmosome and their expression in cultured epithelial cells. J Cell Biol 109:3377-3390

24. Kramer MD, Reinartz J (1993) The autoimmune blistering disease bullous pemphigoid. The presence of plasmin/2-antiplasmin complexes in skin blister fluid indicates plasmin generation in lesional skin. J Clin Invest 92:978-983

25. Labib RS, Anhalt GJ, Patel HP, Mutasim DF, Diaz LA (1986) Molecular heterogeneity of bullous pemphigoid antigens as detected by immunoblotting. J Immunol 136:1231-1235

26. Laffitte E, Skaria M, Jaunin F, Tamm K, Saurat JH, Favre B, Borradori L (2001) Autoantibodies to the extracellular and intracellular domain of bullous pemphigoid 180, the putative key autoantigen in bullous pemphigoid, belong predominantly to the IgG1 and IgG4 subclasses. Br J Dermatol 144:760-768

27. Lauharanta J, Salonen EM, Vaheri A (1989) Plasmin-like proteinase associated with high molecular weight complexes in blister fluid of bullous pemphigoid. Acta Dermato-Venereologica 69:527-529

28. Lever WF (1953) Pemphigus. Medicine 32:1-123

29. Lin MS, Fu CL, Giudice GJ, Olague-Marchan M, Lazaro AM, Stastny P, Diaz LA (2000) Epitopes targeted by bullous pemphigoid $\mathrm{T}$ lymphocytes and autoantibodies map to the same sites on the bullous pemphigoid 180 ectodomain. J Invest Dermatol 115:955961

30. Liu Z, Diaz LA, Troy JL, Taylor AF, Emery DE, Fairley JA, Giudice GJ (1993) A passive transfer model of the organ-specific autoimmune disease, bullous pemphigoid, using antibodies generated against the hemidesmosomal antigen, BP180. J Clin Invest 92:2480-2488

31. Liu Z, Diaz LA, Swartz SJ, Fairley JA, Troy JL, Giudice GJ (1995) Molecular mapping of a pathogenically relevant BP180 epitope associated with experimentally induced murine bullous pemphigoid. J Immunol 155:5449-5454

32. Liu Z, Giudice GJ, Swartz SJ, Fairley JA, Till GO, Troy JL, Diaz LA (1995) The role of complement in experimental bullous pemphigoid. J Clin Invest 95:1539-1544 
33. Liu Z, Giudice GJ, Zhou X, Swartz SJ, Troy JL, Fairley JA, Till GO, Diaz LA (1997) A major role for neutrophils in experimental bullous pemphigoid. J Clin Invest 100:1256-1263

34. Liu Z, Roopenian DC, Zhou X, Diaz LA, Sedmak DD, Anderson CL (1997) $\beta 2$ microglobulin-deficient mice are resistant to bullous pemphigoid. J Exp Med 186:777-783

35. Liu Z, Shipley JM, Vu TH, Zhou X, Diaz LA, Werb Z, Senior RM (1998) Gelatinase B-deficient mice are resistant to experimental BP. J Exp Med 188:475-482

36. Liu Z, Shapiro SD, Zhou X, Twining S, Senior RM, Giudice GJ, Fairley JA, Diaz LA (2000) Neutrophil elastase plays a direct role in dermal-epidermal junction separation in experimental bullous pemphigoid. J Clin Invest 105:113-123

37. Liu Z, Zhou X, Shapiro SD, Shipley JM, Twining SS, Diaz LA, Senior RM, Werb Z (2000) The serpin alpha1-proteinase inhibitor is a critical substrate for gelatinase B/MMP-9 in vivo. Cell 102:647-655

38. Liu Z, Sui W, Zhao M, Li N, Giudice GJ, Fairley JA, Sitaru C, Zillikens D, Marinkovich P, Diaz LA (2006) Induction of bullous pemphigoid and pemphigoid gestationis in humanized BP180NC16A mice by passive transfer of autoantibodies from patients. J Invest Dermatol 126:s21

39. Liu Z, Leighty L, Zhao M, Li N, Fu C, Giudice GJ, Fairley JA, Sitaru C, Zillikens D, Marinkovich P, Diaz LA (2007) Identification of BP180 pathogenic epitope using humanized BP180NC16A mice. J Invest Dermatol 127:s12

40. Mutasim DF, Takahashi Y, Labib RS, Anhalt GJ, Patel HP, Diaz LA (1985) A pool of bullous pemphigoid antigen(s) is intracellular and associated with the basal cell cytoskeleton-hemidesmosome complex. J Invest Dermatol 84:47-53

41. Nelson KC, Zhao M, Schroeder PR, Li N, Wetsel RA, Diaz LA, Liu Z (2006) Role of different pathways of the complement cascade in experimental bullous pemphigoid. J Clin Invest 116:28922900

42. Nishie W, Sawamura D, Goto M, Shibaki A, McMillan JR, Nakamura H, Olasz E, Yancey KB, Akiyama M, Shimizu H (2006) Collagen XVII/BP180 knockout mouse and its transgenic rescue using human collagen XVII cDNA. J Invest Dermatol 126:s21

43. Nishie W, Sawamura D, Goto M, Ito K, Shibaki A, McMillan JR, Sakai K, Nakamura H, Olasz E, Yancey KB, Akiyama M, Shimizu H (2007) Humanization of autoantigen. Nat Med 13:378-383

44. Oikarinen AI, Zone JJ, Ahmed AR, Kiistala U, Uitto J (1983) Demonstration of collagenase and elastase activities in blister fluids from bullous skin diseases. Comparison between dermatitis herpetiformis and bullous pemphigoid. J Invest Dermatol 81:261266

45. Schaefer BM, Jaeger C, Drepper E, Kramer MD (1996) Plasminogen activation in bullous pemphigoid immunohistology reveals urokinase type plasminogen activator, its receptor and plasminogen activator inhibitor type- 2 in lesional epidermis. Autoimmunity 23:155-164

46. Schmidt E, Ambach A, Bastian B, Brocker EB, Zillikens D (1996) Elevated levels of interleukin-8 in blister fluid of bullous pemphigoid compared with suction blisters of healthy control subjects. J Am Acad Dermatol 34:310-312

47. Schmidt E, Bastian B, Dummer R, Tony HP, Brocker EB, Zillikens D (1996) Detection of elevated levels of IL-4, IL-6, and IL10 in blister fluid of bullous pemphigoid. Arch Dermatol Res 288:353-357

48. Schmidt E, Mittnacht A, Schomig H, Dummer R, Brocker EB, Zillikens D (1996) Detection of IL-1 alpha, IL-1 beta, and IL-1 receptor antagonist in blister fluid of bullous pemphigoid. J Dermatol Sci 11:142-147
49. Schmidt E, Obe K, Brocker EB, Zillikens D (2000) Serum levels of autoantibodies to BP180 correlate with disease activity in patients with bullous pemphigoid. Arch Dermatol 136:174-178

50. Shimanovich I, Mihai S, Oostingh GJ, Ilenchuk TT, Brocker EB, Opdenakker G, Zillikens D, Sitaru C (2004) Granulocyte-dervied elastase and gelatinase $\mathrm{B}$ are required for dermal-epidermal separation induced by autoantibodies from patients with epidermolysis bullosa acquisita and bullous pemphigoid. J Pathol 204:519-527

51. Sitaru C, Schmidt E, Petermann S, Munteanu LS, Brocker EB, Zillikens D (2002) Autoantibodies to bullous pemphigoid antigen 180 induce dermal-epidermal separation in cryosections of human skin. J Invest Dermatol 118:664-6671

52. Ståhle-Bäckdahl M, Inoue M, Giudice GJ, Parks WC (1994) $92-$ $\mathrm{kD}$ gelatinase is produced by eosinophils at the site of blister formation in bullous pemphigoid and cleaves the extracellular domain of recombinant $180-\mathrm{kD}$ bullous pemphigoid autoantigen. J Clin Invest 93:2022-2030

53. Stanley JR, Hawley-Nelson P, Yuspa SH, Shevach EM, Katz SI (1981) Characterization of bullous pemphigoid antigen: a unique basement membrane protein of stratified epithelia. Cell 24:897-903

54. Stanley JR, Woodley DT, Katz SI (1984) Identification and partial characterization of pemphigoid antigen extracted from normal human skin. J Invest Dermatol 82:108-111

55. Stanley JR (1999) Bullous pemphigoid. In: Freedberg IM, Eisen AZ, Wolff K, Austen KF, Goldsmith LA, Katz SI (eds) Fitzpatrick's dermatology in general medicine. McGraw-Hill, New York, pp 666-671

56. Tanaka T, Korman NJ, Shimizu H, Eady AJ, Klaus-Kovtun V, Cehrs K, Stanley JR (1990) Production of rabbit antibodies against carboxy-terminal epitopes encoded by bullous pemphigoid cDNA. J Invest Dermatol 94:617-623

57. Verraes S, Hornebeck W, Polette M, Borradori L, Bernard P (2001) Respective contribution of neutrophil elastase and matrix metalloproteinase 9 in the degradation of BP180 (type XVII collagen) in human bullous pemphigoid. J Invest Dermatol 117:10911096

58. Wakugawa M, Nakamura K, Hino H, Toyama K, Hattori N, Okochi H, Yamada H, Hirai K, Tamaki K, Furue M (2000) Elevated levels of eotaxin and interleukin-5 in blister fluid of bullous pemphigoid: correlation with tissue eosinophilia. $\mathrm{Br} \mathrm{J}$ Dermatol 143:112-116

59. Wintroub BU, Mihm MC Jr, Goetzl EJ, Soter NA, Austen KF (1978) Morphologic and functional evidence for release of mast cell products in bullous pemphigoid. N Engl J Med 298:417-421

60. Yamamoto K, Inoue N, Masuda R, Fujimori A, Saito T, ImajohOhmi S, Shinkai H, Sakiyama H (2002) Cloning of hamster type XVII collagen cDNA, and pathogenesis of anti-type XVII collagen antibody and complement in hamster bullous pemphigoid. J Invest Dermatol 118:485-492

61. Zhao M, Trimbeger ME, Li N, Diaz LA, Shapiro SD, Liu Z (2006) Role of FcRs in animal model of autoimmune bullous pemphigoid. J Immunol 177:3398-3405

62. Zillikens D, Ambach A, Schuessler M, Dummer R, Hartmann AA, Burg G (1992) The interleukin-2 receptor in lesions and serum of bullous pemphigoid. Arch Dermatol Res 284:141-145

63. Zillikens D, Rose PA, Balding SD, Olague-Marchan M, Mascaro JM Jr, Liu Z, Diaz LA, Giudice GJ (1997) Tight clustering of extracellular BP180 epitopes recognized by bullous pemphigoid autoantibodies. J Invest Dermatol 109:573-579

64. Zone JJ, Taylor T, Hull C, Schmidt L, Meyer L (2007) IgE basement membrane zone antibodies induce eosinophil infiltration and histological blisters in engrafted human skin on SCID mice. J Invest Dermatol 127:1167-1174 